\title{
The role of hSCs in promoting neural differentiation of hUC-MSCs in spinal cord injury
}

\author{
This article was published in the following Dove Press journal: \\ Journal of Neurorestoratology \\ 8 November 2013 \\ Number of times this article has been viewed
}

\author{
Qiuli $W u^{1, *}$ \\ You Chen ${ }^{1, *}$ \\ Guangzhi Ning' \\ Shiqing Feng' \\ Junling $\mathrm{Han}^{2}$ \\ Qiang $\mathrm{Wu}^{\prime}$ \\ Yulin $\mathrm{Li}^{\prime}$ \\ Hong $\mathrm{Wu}^{\prime}$ \\ Hongyu Shi' \\ 'Department of Orthopedics, Tianjin \\ Medical University General Hospital \\ Tianjin, People's Republic of China; \\ ${ }^{2}$ Tianjin Union Stem Cell and Gene \\ Engineering Co., Ltd, Tianjin, People's \\ Republic of China \\ * These authors contributed equally \\ to this paper
}

Correspondence: Shiqing Feng Department of Orthopedics, Tianjin Medical University General Hospital, I54 Anshan Road, Heping District, Tianjin 300052, People's Republic of China Email fengsq321@gmail.com

\begin{abstract}
Cell therapy is a promising approach to treating spinal cord injury (SCI). Previous studies demonstrated that co-transplantation of human umbilical cord mesenchymal stem cells (hUC-MSCs) and human Schwann cells (hSCs) was an effective strategy by which to promote the regeneration of corticospinal fibers and locomotor recovery after SCI in rats. However, the neural differentiation potential of hUC-MSCs was not fully understood. In the present study, we examined the influence of hSCs on the survival and differentiation of hUC-MSCs in SCI rats. Four groups of rats were implanted with Dulbecco's Modified Eagle's Medium (DMEM), hSCs, hUC-MSCs, or a combination of hSCs and hUC-MSCs, respectively. Our results demonstrated that MAB1281 immunopositive cells appeared in the injured site of the transplanted cell groups, while myelin basic protein and high-molecular-weight neurofilament immunopositive cells were detected only in the co-transplantation group under the positive background of MAB1281. Furthermore, polymerase chain reaction (PCR) and Western blot showed significantly higher expression of myelin basic protein and high-molecular-weight neurofilament and lower expression of glial fibrillary acidic protein in the co-transplantation group $(P<0.05)$, which correlated strongly with immunofluorescence findings. These results suggest that hSCs could induce hUC-MSC differentiation into neurons and oligodendrocytes and inhibit the formation of glial scarring after SCI. The neural differentiation of hUC-MSCs is likely induced by soluble factors provided by hSCs.
\end{abstract}

Keywords: spinal cord injury, Schwann cell, human umbilical cord mesenchymal stem cell, cell transplantation, neural differentiation

\section{Introduction}

People suffering from spinal cord injury (SCI) are prone to permanent paralysis and disability due to the limited regenerative ability of the cord. Self-restoration is greatly decreased because of an absolute loss of neurons and glia. Cell transplantation, as a therapeutic approach in SCI, has attracted much research attention because the transplanted cells possess an ability to accommodate the need for cell replacement. Schwann cells (SCs), the myelin-forming glial cells of the peripheral nervous system, ${ }^{1}$ play a key role in Wallerian degeneration and subsequent regeneration. ${ }^{2}$ Zurita et al obtained evidence that SCs could promote the neural differentiation of bone marrow stromal cell $^{3}$ due to the release of brain-derived neurotrophic factor (BDNF) and nerve growth factor (NGF). ${ }^{4,5}$ Human umbilical mesenchymal stem cells (hUC-MSCs), another promising stem cell, could be more easily obtained and processed than embryonic or bone marrow stromal cells. Previous studies have proven that the transplanted hUCMSCs could trigger axons to grow across the permissive-inhibitory border and promote 
recovery of hind limb locomotor function in injured rats. ${ }^{6,7}$ hUC-MSCs are capable of differentiating into osteogenic, adipogenic, myogenic, and neuron-like cells in vitro. ${ }^{8,9}$ The repair ability and axonal differentiation potential of hUCMSCs, however, is not sufficient to allow substantial recovery following SCI. ${ }^{9,10}$ Although Zhu et al previously demonstrated that co-transplantation of autologous activated SCs and hUC-MSCs could effectively promote the regeneration of corticospinal fibers and the recovery of locomotor function after SCI, ${ }^{11}$ their findings did not provide evidence that SCs could induce the neural differentiation of hUC-MSCs.

This study was carried out to investigate the possible influence of human SCs (hSCs) on the survival and differentiation of hUC-MSCs in SCI rats as well as the expression change of glial fibrillary acidic protein (GFAP), myelin basic protein (MBP), and high-molecular-weight neurofilament $(\mathrm{NF}-\mathrm{H})$.

\section{Materials and methods Animal groups}

Sixty adult Wistar rats (female, $250 \pm 10 \mathrm{~g}$, provided by Radiation Study Institute-Animal Center, Tianjin, People's Republic of China) were randomly and evenly assigned to four experimental groups (15 adult rats in each group), which were as follows: group A, Dulbecco's Modified Eagle's Medium (DMEM) control group; group $\mathrm{B}, \mathrm{hSC}$ transplantation group; group $\mathrm{C}$, hUC-MSC transplantation group; and group $\mathrm{D}, \mathrm{hSC}$ and hUC-MSC co-transplantation group.

\section{Cell culture and purification}

For culture of SCs, the stump sciatic nerves were obtained under aseptic condition from those patients who had lower limbs amputated. After the epineurium of the nerve tissue was peeled off, the remaining nerve tissue was cut into small pieces $\left(0.5 \sim 1 \mathrm{~mm}^{3}\right)$. The tissue lumps were digested with trypsin (College of Life Sciences, Nankai University, Tianjin, People's Republic of China) for 20-30 minutes and then attached to the bottom of 6-well culture plates precoated with polylysine. hSCs were propagated in DMEM supplemented with $10 \%$ fetal bovine serum. The cells were incubated at $37.8^{\circ} \mathrm{C}, 5 \% \mathrm{CO}_{2}$; the culture medium was replaced every 3 days. When hSCs reached confluence of $90 \%$, fifth-passage cells were induced. The cells were purified by differential adhesion. After five passages, the purity of hSCs was identified by S-100 (Boster Biological Technology, Ltd., Wuhan, People's Republic of China) immunostaining and the number of S-100-positive cells and total cells were counted under fluorescence microscopy. After five passages, cells with a density of $1.0 \times 10^{5} / \mu \mathrm{L}$ were used in this experiment.

$$
\begin{aligned}
\mathrm{hSC} \text { purity }(\%)= & \mathrm{S}-100-\text { positive cells } / \\
& \text { total cells } \times 100 \% \text {. }
\end{aligned}
$$

hUC-MSCs were donated by the Tianjin Union Stem Cell and Gene Engineering Co., Ltd (Tianjin, People's Republic of China) and cells with a density of $1.0 \times 10^{5} / \mu \mathrm{L}$ were used in this experiment.

\section{Identification of SCs}

hSCs were cultured on a cover slip for 48 hours, washed three times with $0.01 \mathrm{M}$ phosphate-buffered solution (PBS), and then postfixed with $4 \%$ paraformaldehyde $(\mathrm{pH} 7.4)$ for 4 hours at room temperature. The cell cover slip was then covered with $0.1 \%$ Triton $\mathrm{X}-100$ for 15 minutes at room temperature and blocked with 5\% goat serum albumin for 10 minutes to block the nonspecific antigen. Primary antibody (rabbit anti-rat S-100 immunoglobulin [Ig]G 1:50; SigmaAldrich, St Louis, MO, USA) was added to the slides, which were then incubated at $37^{\circ} \mathrm{C}$ for 30 minutes. Secondary antibody (goat anti-rabbit IgG/FITC 1:100; Sigma-Aldrich) was added to the slides for 10 minutes at $37^{\circ} \mathrm{C}$. The slides were observed with fluorescence microscopy.

\section{Preparation for $\mathrm{SCl}$ model and cell grafting}

The Wistar rats were anesthetized by intraperitoneal injection with $10 \%$ chloral hydrate $(0.33 \mathrm{~mL} / 100 \mathrm{~g})$. The surgical area was shaved and disinfected with iodophor. The spinous process and vertebral plate were removed using a microrongeur (Aesculap AG, Tuttlingen, Germany) at T10 and the dura was opened. Then, the NYU impactor machine (WM Keck Center for Collaborative Neuroscience, Piscataway Township, NJ, USA) was used to hit the exposed spinal cord with $10 \mathrm{~g} \times 50 \mathrm{~mm}$ weight drop. A total of $10 \mu \mathrm{L}$ DMEM, $5 \mu \mathrm{L}$ hSC cell suspension plus $5 \mu \mathrm{L}$ DMEM, $5 \mu \mathrm{L}$ hUC-MSCs plus $5 \mu \mathrm{L}$ DMEM, $5 \mu \mathrm{L}$ hSC plus $5 \mu \mathrm{L}$ hUCMSCs suspension (with a cell density of $1.0 \times 10^{5} / \mu \mathrm{L}$ ) was injected into the $1 \mathrm{~cm}$ length caudal and rostra to the SCI site with a Hamilton injector (Shanghai Precision and Scientific Instrument Co., Ltd, Shanghai, People's Republic of China) at a $45^{\circ}$ angle. After the injection, the needle was indwelled for 3 minutes, after which the incision was sutured layer by layer. After surgery, rats were placed in temperature- and humidity-controlled incubation chambers until they awoke. They were then transferred to cages, and bladder evacuation 
was performed daily until return of reflexive bladder control. Three days before cell grafting, the rats were injected with cyclosporine A $(10 \mathrm{mg} / \mathrm{kg})$ until the end of the experiment.

\section{Histological analysis}

Rats were sacrificed with an overdose of $10 \%$ chloral hydrate by intraperitoneal injection and perfused transcardially with 4\% neutral PFA in 0.01 M PBS, pH 7.4, 2 and 4 weeks after the cell grafting, respectively. A $1.5 \mathrm{~cm}$ length of the spinal cord centered at the injury site was separated and embedded in a paraffin-embedding machine (Leica Microsystems, Wetzlar, Germany). Paraffin sections $(5 \mu \mathrm{m})$ were cut with microtome (Leica Microsystems) and mounted onto gelatinsubbed slides. For immunostaining, we picked up one of the 15 th to 20 th slices, including the injured area from dorsal to ventral side of the spinal cord, to reduce the influence of error. Three coronal sections in each group were used for hematoxylin and eosin staining. Six cross-sections in each group were stained for GFAP, MBP, and NF-H (Santa Cruz Company, CA, USA) immunoreactivity staining, respectively.

\section{Western blotting}

Rats were randomly sacrificed in each group as per the method described above. One hundred fifty micrograms of the immunoblotting tissue was lysed in ice-cold lysis buffer. The homogenate was centrifuged at $12,000 \mathrm{r}$ for 20 minutes at $4^{\circ} \mathrm{C}$, then the supernatants were collected and heated at $100^{\circ} \mathrm{C}$ for 5 minutes. Protein $(20 \mu \mathrm{L} /$ well $)$ was loaded in sodium dodecyl sulfate-polyacrylamide gel electrophoresis and run in running buffer. Gels were transferred to nitrocellulose membrane. The membranes were blocked with 5\% nonfat skim milk in PBS and then incubated with primary antibodies overnight at $4^{\circ} \mathrm{C}$. The following morning, blots were processed with horseradish peroxidase-conjugated secondary antibodies for 2 hours at room temperature. $\beta$-actin antibody was used as an internal control.

\section{Real-time polymerase chain reaction (PCR)}

For real-time PCR (LightCycler ${ }^{\circledR}$; Bio-Rad Laboratories, Inc., Hercules, CA, USA), the spinal cord (about $25 \mu \mathrm{g}$ ) was removed at the caudal and rostra of the injury site. Each RNA sample ( $2 \mu \mathrm{g}$ total) was extracted with an RNA extraction kit (QIAGEN Co. Ltd., Shanghai, People's Republic of China) for reverse transcription reaction, according to the manufacturer's instructions. The acquired complementary DNA (cDNA) was used for the real-time PCR. The reaction system (total $25 \mu \mathrm{L}$ ) included $2 \mu \mathrm{L}$ cDNA, $8.5 \mu \mathrm{L} \mathrm{ddH}_{2} \mathrm{O}_{2}, 1 \mu \mathrm{L} 10$ pm upstream primer, $1 \mu \mathrm{L}$ downstream primer, and $12.5 \mu \mathrm{L}$ SYBR Green fluorescent dye (Table 1). The amplification conditions were $95^{\circ} \mathrm{C}$ for 3 minutes; 40 cycles of $95^{\circ} \mathrm{C}$ for 15 seconds, $60^{\circ} \mathrm{C}$ for 20 seconds, and $72^{\circ} \mathrm{C}$ for 20 seconds; $95^{\circ} \mathrm{C}$ for 1 minute and $60^{\circ} \mathrm{C}$ for 1 minute; and $60^{\circ} \mathrm{C}$ to $95^{\circ} \mathrm{C}$ and again to $60^{\circ} \mathrm{C}$ for 71 cycles. The run was completed with descending to $25^{\circ} \mathrm{C}$. The control experiments were carried out with GADPH.

\section{Data analysis}

Data were analyzed with SPSS software (v 16.0; IBM Corporation, Armonk, NY, USA) and presented as mean \pm standard deviation. The different time comparisons among each group were analyzed by analysis of variance (ANOVA) and SNK-q. Statistical significance was set at $P<0.05$.

\section{Results}

\section{Culture, purity, and identification of hSCs}

Three days after the primary passage culture, a few SCs showed outside the rim of the tissue lumps and showed a spindle shape under the microscope (Figure 1A). Within the following 5 days, the cells proliferated and covered the entire bottom of the 6-well plates. The outlines of the hSCs were clear and bright, with some of the cells presenting with a whirlpool shape. After purification by differential adhesion method, the cells were arranged side-by-side and demonstrated directionality; the morphous of hSCs appeared more unified; and the number of fibroblasts had decreased obviously (Figure 1B). After five passages, the hSCs exhibited stable expression of S-100 antigen and the purity of hSCs reached more than 90\% (Figure 1C)

\section{Biological characters of hUC-MSCs}

hUC-MSCs appear as spherical, star-like, or elongated flat fibroblast like morphology with granules on the surfaces that have neither protrusions nor networks between the cells.

Table I The primer of the markers

\begin{tabular}{lll}
\hline & Upstream primer & Downstream primer \\
\hline GFAP & GTGGGCAGGTGGGAGCTTGATTCT & CTGGGGCGGCCTGGTATGACA \\
MBP & TTAGCTGAATTCGCGTGTGG & GAGGAAGTGAATGAGCCGGTTA \\
NF-H & TGAACACAGAACGCTATGCGCTCAG & CACCTTTATGTGAGTGGACACAGAG \\
\hline
\end{tabular}

Abbreviations: GFAP, glial fibrillary acidic protein; MBP, myelin basic protein; NF-H, high-molecular-weight neurofilament. 

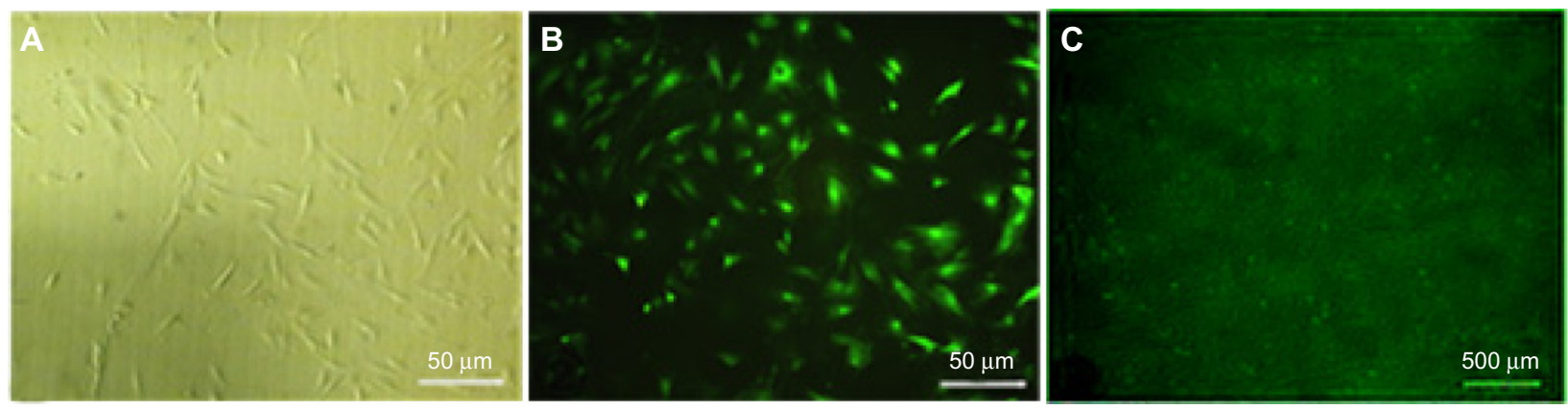

Figure I Culture and identification of human Schwann cells (hSCs).

Notes: (A) Morphology of hSCs at 3 days post-culture; (B) S-100 immunofluorescence staining of the fifth passage (P), hSCs; (C) five passages of hSCs.

\section{Results of grafted cells tracing in vivo}

Four weeks after cell grafting, one rat in each group was selected for paraffin-embedded section. The grafted cells were traced with MAB1281 staining in vivo. In groups B, C, and $\mathrm{D}, \mathrm{MAB} 1281$-positive cells were aggregated around the injured area of the spinal cord, while group A did not show MAB1281-positive cells (Figure 2), demonstrating that the grafted cells could survive well and migrate to the injury site of the spinal cord.

\section{Observation of immunofluorescence staining}

Four weeks after cell grafting, on the background of MAB1281, immunofluorescence staining of neural (NF-H) and oligodendroglial (MBP) cells was positive in group D, while immunofluorescence expression of MBP and NF-H was absent in the other groups. The response area of GFAP staining did not show up in any of the four groups, indicating the inability of the hUC-MSCs to differentiate to astrocytes.

\section{Real-time PCR results}

After cell grafting, PCR was used to detect the mRNA expression of GFAP, MBP, and NF-H in each group. $\mathrm{Ct}$ was performed according to the format of $2^{-\triangle \Delta C t}$, the final data representing the amount ratio of GFAP-, MBP-, and NF-H-mRNA expression between the second, third, and fourth weeks and the first week in each group. In this study, real-time PCR showed a strong correlation with the immunofluorescence staining findings. In the co-transplantation group, presence of MBP-mRNA and NF-H-mRNA was evident, compared with the other three groups (DMEM, hSC, and hUC-MSC groups) $(P<0.05)$, while the differences of MBP-mRNA and NF-H-mRNA expression in the hSC or hUC-MSC transplantation groups did not show statistical significance $(P>0.05)$, in agreement with the immunofluorescence staining. In contrast, the differences of GFAP-mRNA among the four groups were considered not significant, but it was clear that the transplanted cells could decrease the formation of GFAP to some extent.

\section{Western blot examination}

To confirm the results of RT-PCR, Western blot analysis was performed and the results were in accordance with the immunofluorescence and PCR findings. In the co-transplantation group, MBP and NF-H expression were higher and GFAP was lower than in the other groups, with a significant statistical
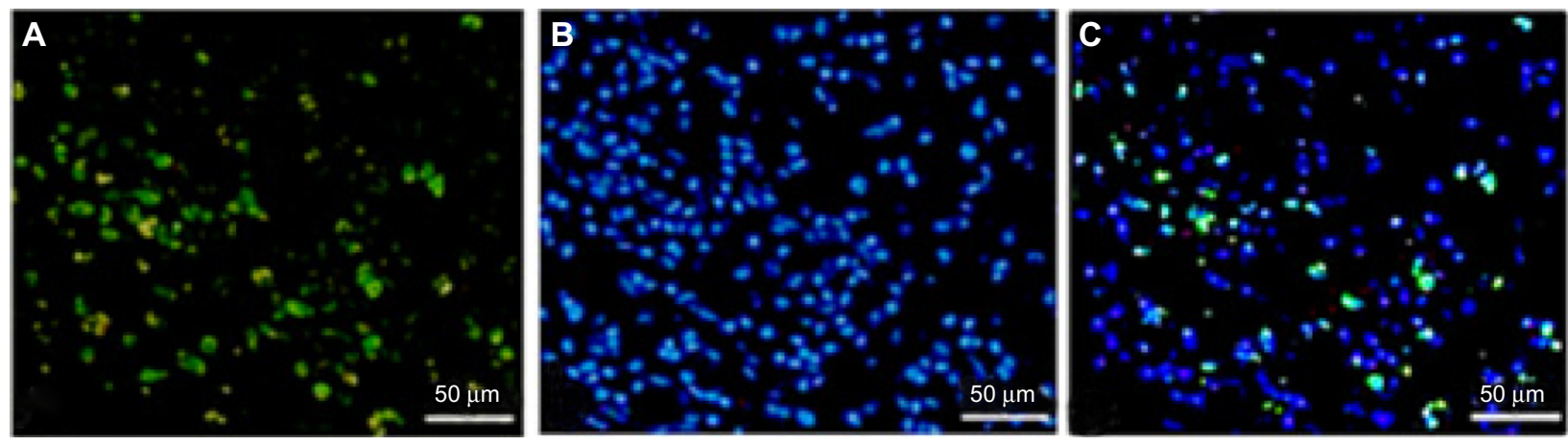

Figure 2 Grafted cell tracing in vivo.

Notes: (A) MABI28I staining; (B) 4',6-diamidino-2-phenylindole (DAPI) staining; (C) MABI28I + DAPI staining. 

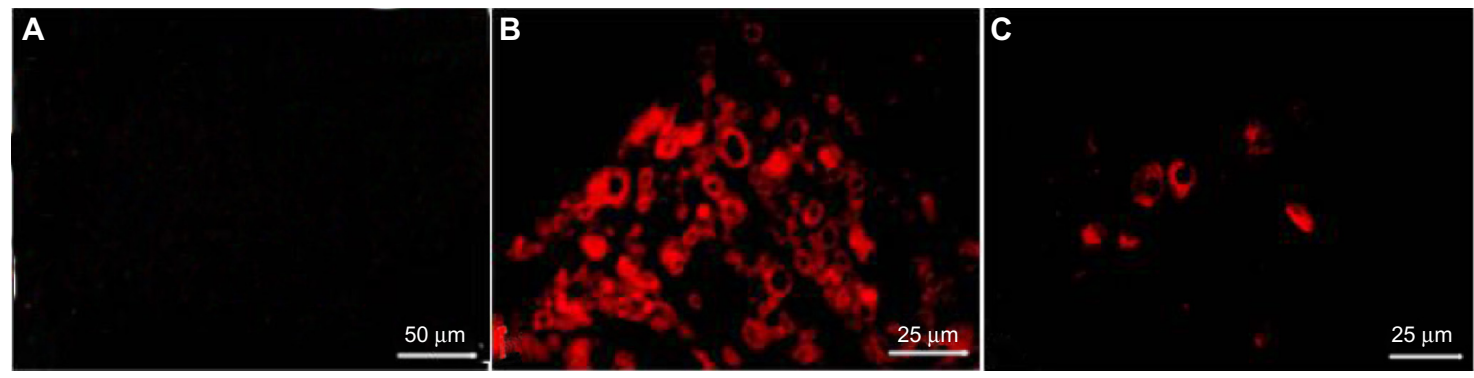

Figure 3 Immunofluorescence staining (group D [hSC and hUC-MSC co-transplantation]).

Notes: (A) Glial fibrillary acidic protein staining; (B) myelin basic protein staining; (C) high-molecular-weight neurofilament staining.

Abbreviations: hSCs, human Schwann cells, hUC-MSC; human umbilical cord mesenchymal stem cells.
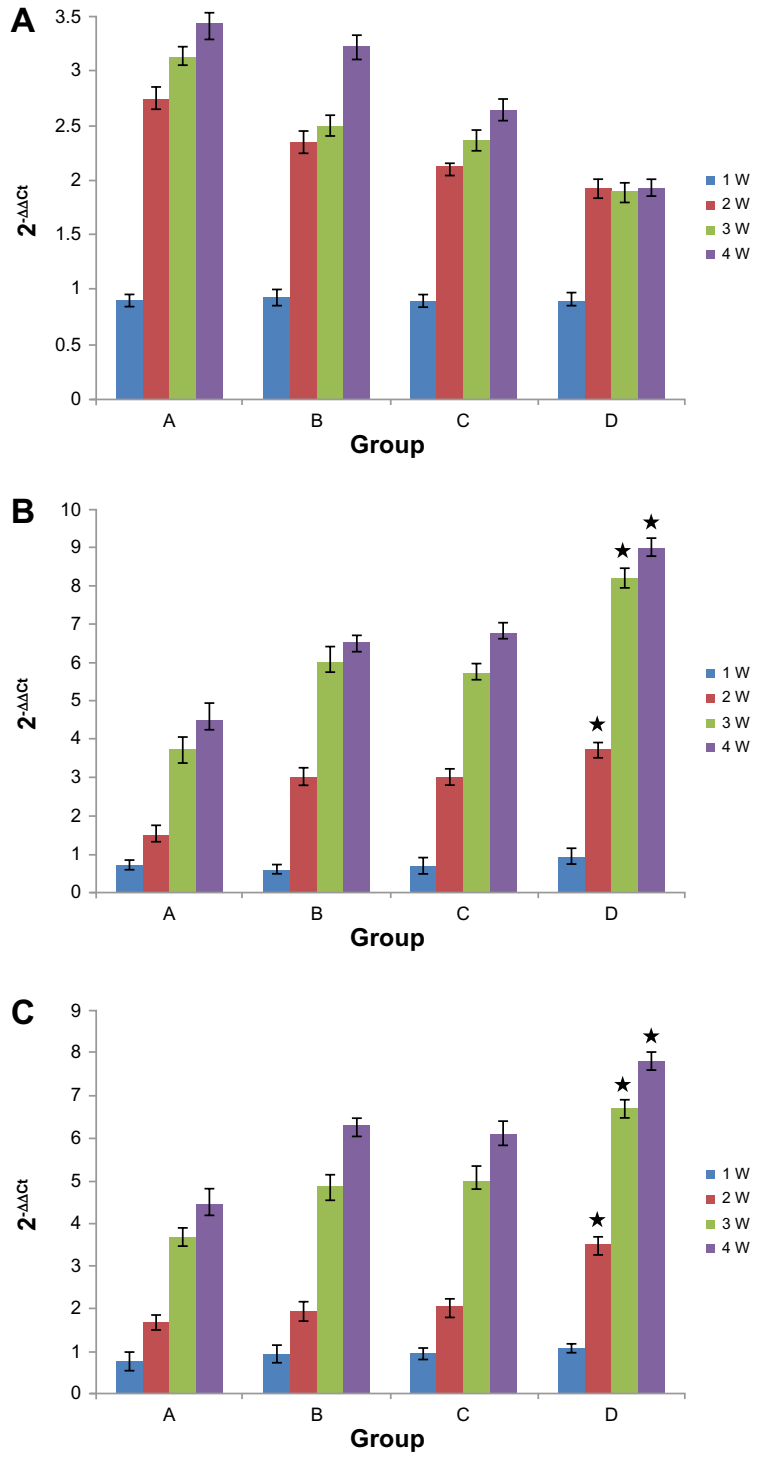

Figure 4 Real-time polymerase chain reaction results.

Notes: mRNA expression at different times in each group of $(\mathbf{A})$ glial fibrillary acidic protein; (B) myelin basic protein; (C) high-molecular-weight neurofilament. The four groups were as follows: group A, Dulbecco's Modified Eagle's Medium control group; group B, hSC transplantation group; group C, hUC-MSC transplantation group; and group D, hSC and hUC-MSC co-transplantation group. The $\mathrm{x}$-axis indicates the different experimental groups, with different colors representing the mRNA expression of myelin basic protein at different times. The $y$-axis represents the $\mathrm{Ct}$ data. $\star$ The difference among the four groups was statistically significant $(P<0.05)$ at different times.

Abbreviations: hSCs, human Schwann cells; hUC-MSC, human umbilical cord mesenchymal stem cells; mRNA, messenger RNA; CT, cycle threshold; W, weeks. difference $(P<0.05)$; however, compared with the DMEM group, the expression of MBP and NF-H in the hSC or hUC-MSC transplantation groups showed no significant differences $(P>0.05)$. The results demonstrate that the protein expression of those neural markers had the same increased tendency with the mRNA.

\section{Discussion}

SCI is followed by primary breakup of axons and secondary inflammation response at the site of injury. The ability of intrinsic cell renewal, ${ }^{8}$ even with the application of mitogenic agents such as epidermal growth factor and fibroblast growth factor- $2,9,10$ is not sufficient for substantial recovery of the SCI. Based on recent studies, stem cell therapy is an option for the treatment strategy of SCI and shows preliminary promise.

SCs not only support axonal regeneration in the injured peripheral nervous system, but also promote axonal regrowth and myelin reconstruction in the injured central nervous system. SCs have been proven to have the ability to facilitate axonal regeneration with secreted neurotropic factors, such as BDNF and NGF. ${ }^{12}$ The results of a previous experiment ${ }^{13}$ showed that transplantation of autologous activated SCs could promote the recovery of hind limb locomotor function in injured rats and that the regenerative neurofilaments could pass through the injury site and make up the spinal cord cavity. Through co-culturing neural stem cells and SCs in vitro, SCs could promote the survival, regeneration, and neural differentiation of the neural stem cells. ${ }^{14}$

HU-MSCs can be easily obtained, isolated, and processed without any ethical or legal problem, in contrast to embryonic or bone marrow stem cells. The fibroblast colony-forming unit of hUC-MSCs has a high isolation rate and short doubling time. ${ }^{11,15}$ For the other aspects, hUC-MSCs are immunologically compatible and capable of long-term survival in the host tissue. hUC-MSCs could also express the primitive stem cell-related marker protein. ${ }^{16}$ Thus, hUC-MSCs are a promising candidate stem cell for the treatment of SCI. 
A

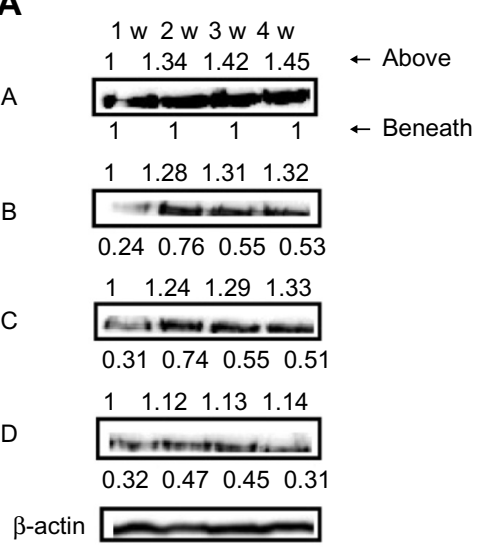

B

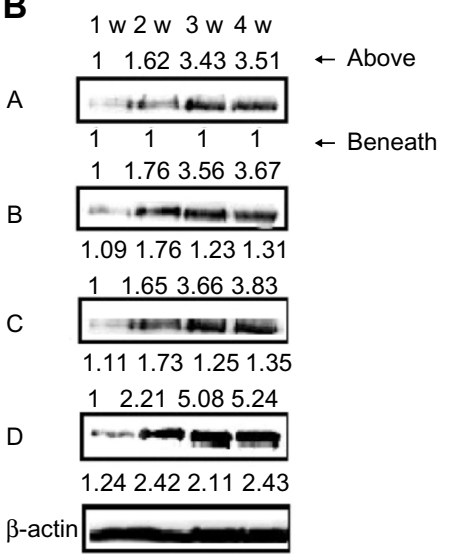

C

1 w 2 w 3 w 4 w

A

1 1.76 4.12 4.21

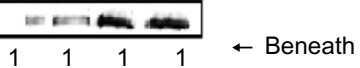

B

$1 \quad 1.563 .25 \quad 3.31$

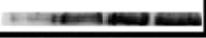

1.562 .491 .551 .57

$\begin{array}{llll}1 & 1.52 & 2.73 & 2.79\end{array}$

C

-4.

1.582 .621 .511 .73

$1 \quad 1.312 .132 .21$

D

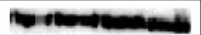

2.433 .472 .112 .31

$\beta$-actin

Figure 5 Western blot.

Notes: (A) Glial fibrillary acidic protein staining (50 kDa); (B) myelin basic protein (2l.5 kDa); (C) high-molecular-weight neurofilament (200 kDa). The letters A-D in each figure part correspond to the four study groups, which were as follows: group A, Dulbecco's Modified Eagle's Medium control group; group B, hSC transplantation group; group C, hUC-MSC transplantation group; and group D, hSC and hUC-MSC co-transplantation group. The number above each band represents the grey degree ratio of the protein expression between the second, third, and fourth weeks, respectively, and the first week in each group; the number beneath the band represents the grey degree ratio of the experimental groups and the control group at the corresponding time points.

Abbreviations: hSCS, human Schwann cells; hUC-MSC, human umbilical cord mesenchymal stem cells; w, weeks.

Controversy still exists, however, regarding the possibility and rate of transdifferentiation of hUC-MSCs into neurons. Yang et al have demonstrated that only grafted hUC-MSCs could not differentiate to the neural cell. ${ }^{17}$ However, another in vitro experiment indicated that hUC-MSCs could express neuron-specific proteins, such as microtubule-associated protein and neurofilament. Moreover, glutamate-invoking inward current has also been found in transformed cells, suggesting that the induced cells could differentiate into mature neurons. ${ }^{18}$ In the present study, immunofluorescence staining demonstrated that co-transplantation of hSCs and hUCMSCs could promote hUC-MSC differentiation into neurons and glial cells, which was confirmed with RT-PCR and Western blot analysis. This might be a result of neurotropic factors secreted by the hSCs, which improved the inhibitory microenvironment of the injured spinal cord. ${ }^{19}$ This result shows some accordance with the findings of Kadivar et $\mathrm{al}^{20}$ and Koh et al, ${ }^{21}$ who documented the potential capacities of human umbilical cord vein-derived MSCs differentiating into neural cells. In another aspect, hUC-MSC transdifferentiation with chemical agent is a quick induction process that has attracted much research attention. Wang et $\mathrm{al}^{22}$ indicated that neuron-specific enolase and neurofilament $\mathrm{M}$ could be detected after culturing hUC-MSCs with basic fibroblast growth factor and low serum media plus butylated hydroxyanisole and dimethyl sulfoxide. This illustrates that these modifications could be a result of the induced chemical neurotropic factors. Since adult SCs can release neurotropic factors such as BDNF and NGF, ${ }^{5}$ there is a great possibility that neuronal transdifferentiation of hUC-MSCs and recovery of neurological function could be obtained in vivo when they are grafted into neural tissue with the SCs after SCI. Moreover, the change in protein expression of MBP, $\mathrm{NF}-\mathrm{H}$, and GFAP in the co-transplantation group illustrates that the co-transplantation of hUC-MSCs and hSCs not only made up the loss of neurons and oligodendrocytes, but also inhibited the formation of glial scarring.

\section{Conclusion}

The present research demonstrates that hUC-MSCs can transdifferentiate into neurons and glial cells in vivo when co-cultured with hSCs in injured neural tissue. Therefore, it suggests that, as a cell therapy protocol, induced neural transdifferentiation procedures of hUC-MSCs in vitro may not be necessary, and the prospect of widespread application of $\mathrm{hUC}-\mathrm{MSCs}$ and hSCs in the treatment of SCI is promising.

\section{Acknowledgments}

This study was supported by the National Natural Science Foundation of China, No 30872603; Health Bureau Science Foundation of Tianjin, People's Republic of China, No 09KZ104; Health Bureau Key Science Foundation of Tianjin, People's Republic of China, No 07KG2; and Application Foundation and Cutting-edge Technology Research Key Project of Tianjin, People's Republic of China, No 10JCZDJC18800.

\section{Disclosure}

The authors report no conflicts of interest in this work, and the manuscript was approved for publication by all authors. 


\section{References}

1. Cao FJ, Feng SQ. Human umbilical cord mesenchymal stem cells and the treatment of spinal cord injury. Chin Med J (Engl). 2009;122(2): 225-231.

2. Fu YS, Shih YT, Cheng YC, Min MY. Transformation of human umbilical mesenchymal cells into neurons in vitro. J Biomed Sci. 2004;11(5): 652-660.

3. Zurita M, Vaquero J, Oya S, Bonilla C, Aguayo C. Neurotrophic Schwann-cell factors induce neural differentiation of bone marrow stromal cells. Neuroreport. 2007;18(16):1713-1717.

4. Kleitman N, Bunge MB. Olfactory ensheathing glia: their application to spinal cord regeneration and remyelination strategies. Top Spinal Cord Inj Rehabil. 2000;6:65-81.

5. Xu XM, Zhang SX, Li H, Aebischer P, Bunge MB. Regrowth of axons into the distal spinal cord through a Schwann cell-seeded mini-channel implanted into hemisected adult rat spinal cord. Eur J Neurosci. 1999;11(5):1723-1740.

6. Lin CH, Cheng FC, Lu YZ, Chu LF, Wang CH, Hsueh CM. Protection of ischemic brain cells is dependent on astrocyte-derived growth factors and their receptors. Exp Neurol. 2006;201(1):225-233.

7. Zhu YH, Feng SQ, Kong XH, et al. Repair of spinal cord injury with co-transplantation of human umbilical cord mesenchymal stem cells. Chin J Orthop Trauma. 2009;11:747-751.

8. Horner PJ, Power AE, Kempermann G, et al. Proliferation and differentiation of progenitor cells throughout the intact adult rat spinal cord. J Neurosci. 2000;20(6):2218-2228.

9. Kojima A, Tator CH. Epidermal growth factor and fibroblast growth factor 2 cause proliferation of ependymal precursor cells in the adult rat spinal cord in vivo. J Neuropathol Exp Neurol. 2000;59(8): 687-697.

10. Martens DJ, Seaberg RM, van der Kooy D. In vivo infusions of exogenous growth factors into the fourth ventricle of the adult mouse brain increase the proliferation of neural progenitors around the fourth ventricle and the central canal of the spinal cord. Eur J Neurosci. 2002;16(6):1045-1057.

11. Zhu YH, Feng SQ, Kong XH, et al. Repair of spinal cord injury with co-transplantation of human umbilical cord mesenchymal stem cells and autologously activated Schwann cells. Chinese Journal of Orthopaedic Trauma. 2009;11(8):747-751.
12. Yamamoto M, Sobue G, Li M, Arakawa Y, Mitsuma T, Kimata K. Nerve growth factor (NGF), brain-derived neurotrophic factor (BDNF) and low-affinity growth factor receptor (LNGFR) mRNA levels in cultured rat Schwann cells; differential time- and dose-dependent regulation by cAMP. Neurosci Lett. 1993;152(1-2):37-40.

13. Ban DX, Kong XH, Feng SQ, Ning GZ, Chen JT, Guo SF. Intraspinal cord graft of autologous activated Schwann cells efficiently promotes axonal regeneration and functional recovery after rat's spinal cord injury. Brain Res. 2009;1256:149-161.

14. Feng SQ, Kong XH, Sun ZH. Co-culture of rat neural stem cells and mouse Schwann cells. Chinese Journal of Experimental Surgery. 2006;23:81-83.

15. Baksh D, Yao R, Tuan RS. Comparison of proliferative and multilineage differentiation potential of human mesenchymal stem cells derived from umbilical cord and bone marrow. Stem Cells. 2007;25(6):1384-1392.

16. Weiss ML, Medicetty S, Bledsoe AR, et al. Human umbilical cord matrix stem cells: preliminary characterization and effect of transplantation in a rodent model of Parkinson's disease. Stem Cells. 2006;24(3): 781-792.

17. Yang CC, Shih YH, Ko MH, Hsu SY, Cheng H, Fu YS. Transplantation of human umbilical mesenchymal stem cells from Wharton's jelly after complete transection of the rat spinal cord. PLoS One. 2008;3(10): e3336.

18. Fu YS, Shih YT, Cheng YC, Min MY. Transformation of human umbilical mesenchymal cells into neurons in vitro. J Biomed Sci. 2004;11(5): 652-660.

19. Guest JD, Hiester ED, Bunge RP. Demyelination and Schwann cell responses adjacent to injury epicenter cavities following chronic human spinal cord injury. Exp Neurol. 2005;192(2):384-393.

20. Kadivar M, Khatami S, Mortazavi Y, Shokrgozar MA, Taghikhani M, Soleimani M. In vitro cardiomyogenic potential of human umbilical vein-derived mesenchymal stem cells. Biochem Biophys Res Commun. 2006;340(2):639-647.

21. Koh SH, Kim KS, Choi MR, et al. Implantation of human umbilical cord-derived mesenchymal stem cells as a neuroprotective therapy for ischemic stroke in rats. Brain Res. 2008;1229:233-248.

22. Wang HS, Hung SC, Peng ST, et al. Mesenchymal stem cells in the Wharton's jelly of the human umbilical cord. Stem Cells. 2004;22(7): 1330-1337.
Journal of Neurorestoratology

\section{Publish your work in this journal}

The Journal of Neurorestoratology is an international, peer-reviewed, open access online journal publishing original research and review articles on the subject of Neurorestoratology. To provide complete coverage of this revolutionary field the Journal of Neurorestoratology will report on relevant experimental research, technological advances, and

\section{Dovepress}

clinical achievements. The manuscript management system is completely online and includes a very quick and fair peer-review system, which is all easy to use. Visit http://www.dovepress.com/testimonials.php to read real quotes from published authors. 